\title{
Reasons for non-vaccination against influenza among older adults with hypertension in Brazil: a cross-sectional study
}

\author{
Aldiane Gomes de Macedo Bacurau', Priscila Maria Stolses Bergamo Francisco" \\ Department of Collective Health, Faculdade de Ciências Médicas (FCM), Universidade Estadual de Campinas (UNICAMP), Campinas (SP), Brazil
}

'MSc. Nurse and Postgraduate Student (doctoral), Department of Collective Health, Faculdade de Ciências Médicas (FCM), Universidade Estadual de Campinas (UNICAMP) Campinas (SP), Brazil.

(D) orcid.org/0000-0002-6671-2284

"PhD. Statistician and Associate Professor, Department of Collective Health, Faculdade de Ciências Médicas (FCM), Universidade Estadual de Campinas (UNICAMP), Campinas (SP), Brazil. (D) orcid.org/0000-0001-7361-9961

KEY WORDS (MeSH terms):

Aged.

Influenza vaccines

Hypertension.

Health surveys.

Vaccination.

Chronic disease.

\section{AUTHORS' KEY WORDS:}

Elderly.

Disease prevention.

High blood pressures.

Awareness, vaccination.

\begin{abstract}
The aim of this study was to estimate the prevalence of non-vaccination against influenza among Brazilian older adults with systemic arterial hypertension and determine the main reasons for non-adherence. A cross-sectional study was conducted using data from older adults ( $\geq 60$ years of age) with hypertension who participated in the 2013 National Health Survey and reported not having been vaccinated against flu over the previous 12 months $(n=1,295)$. The analyses were performed using the Stata 14.0 software. The data were weighted because of the sampling design. An estimated 3,026,080 older adults with hypertension had not received a flu vaccine over the 12 months prior to the survey (22.6\%). No significant associations were found with sex, age group or schooling. The prevalence of unvaccinated older adults was lower in the southern and southeastern regions of Brazil than in the northern and northeastern regions, even after adjusting for age. The prevalence was higher among individuals without private health insurance. The main reasons for non-vaccination were fear of a reaction, rarely having the flu and not believing in the protection of the vaccine. The present findings underscore the need for healthcare professionals to explain to the population the benefits of the vaccine for preventing severe influenza (protective effect and possible reactions) and for secondary prevention of cardiovascular events. Increasing the prevalence of vaccination in older adults with hypertension and other cardiovascular diseases is of fundamental importance within the realm of public health as a strategy for reducing occurrences of complications and deaths associated with influenza.
\end{abstract}

\section{INTRODUCTION}

Systemic arterial hypertension is a major risk factor for other cardiovascular diseases ${ }^{1}$ and is highly prevalent in both adults and elderly people. ${ }^{2,3}$ Data from the Brazilian National Health Survey revealed rates of $44.4 \%, 52.7 \%$ and $55.0 \%$ among Brazilian elderly people aged 60-64, $65-74$ and $\geq 75$ years, respectively, ${ }^{4}$ and the prevalence increased with age $(71.7 \%$ of individuals aged $\geq 70$ years had high blood pressure or reported taking antihypertensive medication). ${ }^{3}$

Individuals with cardiovascular disease are at greater risk of complications from influenza. ${ }^{5,6}$ Besides the risk factors described in the literature (hypertension, obesity, physical inactivity, smoking, etc.), influenza contributes to cardiovascular morbidity and mortality. ${ }^{6}$ The American Heart Association and American College of Cardiology indicate the flu vaccine for individuals with atherosclerotic disease. ${ }^{7}$ The United Kingdom National Clinical Guideline Centre ${ }^{8}$ and the Brazilian Cardiology Society ${ }^{9}$ indicate the vaccine for individuals with heart failure.

Studies have shown that in individuals with cardiovascular disease, the flu vaccine reduces occurrences of cardiovascular events and mortality. ${ }^{6,10}$ Among individuals with hypertension, vaccination prior to the flu season has been significantly associated with reduction of the risk of death due to acute myocardial infarction, stroke and all causes. ${ }^{10}$

In Brazil, the flu vaccine is offered through the public healthcare system to groups that are at risk (elderly people and individuals with chronic respiratory, heart, neurological, liver, kidney and metabolic diseases), as a strategy for prevention of the disease, its severe forms and complications. ${ }^{11}$ Higher rates of vaccination among individuals with hypertension have been observed since these campaigns began. ${ }^{12,13}$

Since hypertension is a chronic disease that requires follow-up and treatment, most older adults in Brazil are dependent on the public healthcare system ${ }^{14}$ and primary care is the main source of antihypertensive medications. ${ }^{15}$ Thus, it can be hypothesized that this group is more attentive to information on vaccination campaigns and other offers from public healthcare services. However, after two decades of vaccine campaigns, approximately $20 \%$ of elderly people 
with hypertension are not receiving the vaccine, and this percentage has remained stable over the years. ${ }^{12,16}$

\section{OBJECTIVE}

The aim of the present study was to estimate the prevalence of non-vaccination against influenza among older Brazilians with hypertension and determine the main reasons for non-adherence.

\section{METHODS}

A cross-sectional study was conducted using public domain data on elderly people ( $\geq 60$ years) who participated in the 2013 National Health Survey, ${ }^{17}$ reported having hypertension $(\mathrm{n}=5,524)$ and reported having not been vaccinated against influenza over the previous 12 months $(n=1,295)$. We estimated the absolute number and proportion of non-vaccinated elderly people with hypertension and the respective 95\% confidence intervals, according to sociodemographic characteristics, and determined the reasons for non-vaccination.
All estimates were made using the Stata 14.0 software and took the sampling design into consideration. The National Health Survey had received approval from the National Ethics Committee of the Health Ministry (certificate number: 328.159; June 26, 2013).

\section{RESULTS}

The mean age of the elderly people with hypertension was 70.3 years (95\% confidence interval, CI: 70.0-70.7), and $61.0 \%$ (95\% CI: 58.8-63.2) were women. It was estimated that 3,026,080 elderly people with hypertension had not been vaccinated against influenza (22.6\%; 95\% CI: 20.9-24.5). No significant associations were found in relation to sex $(\mathrm{P}=0.373)$, age group $(\mathrm{P}=0.456)$ or schooling $(\mathrm{P}=0.138)$. In comparison with the northern region of the country (27.9\% not vaccinated), the prevalence of non-vaccinated elderly people was lower in the southern and southeastern regions ( $16.7 \%$ and $20.8 \%$, respectively), even after adjusting for age. The prevalence of non-vaccination was higher among individuals without private health insurance $\mathrm{P}=0.026$ (Table 1).

Table 1. Vaccination against influenza among older Brazilians with hypertension, according to sociodemographic characteristics. National Health Survey, 2013

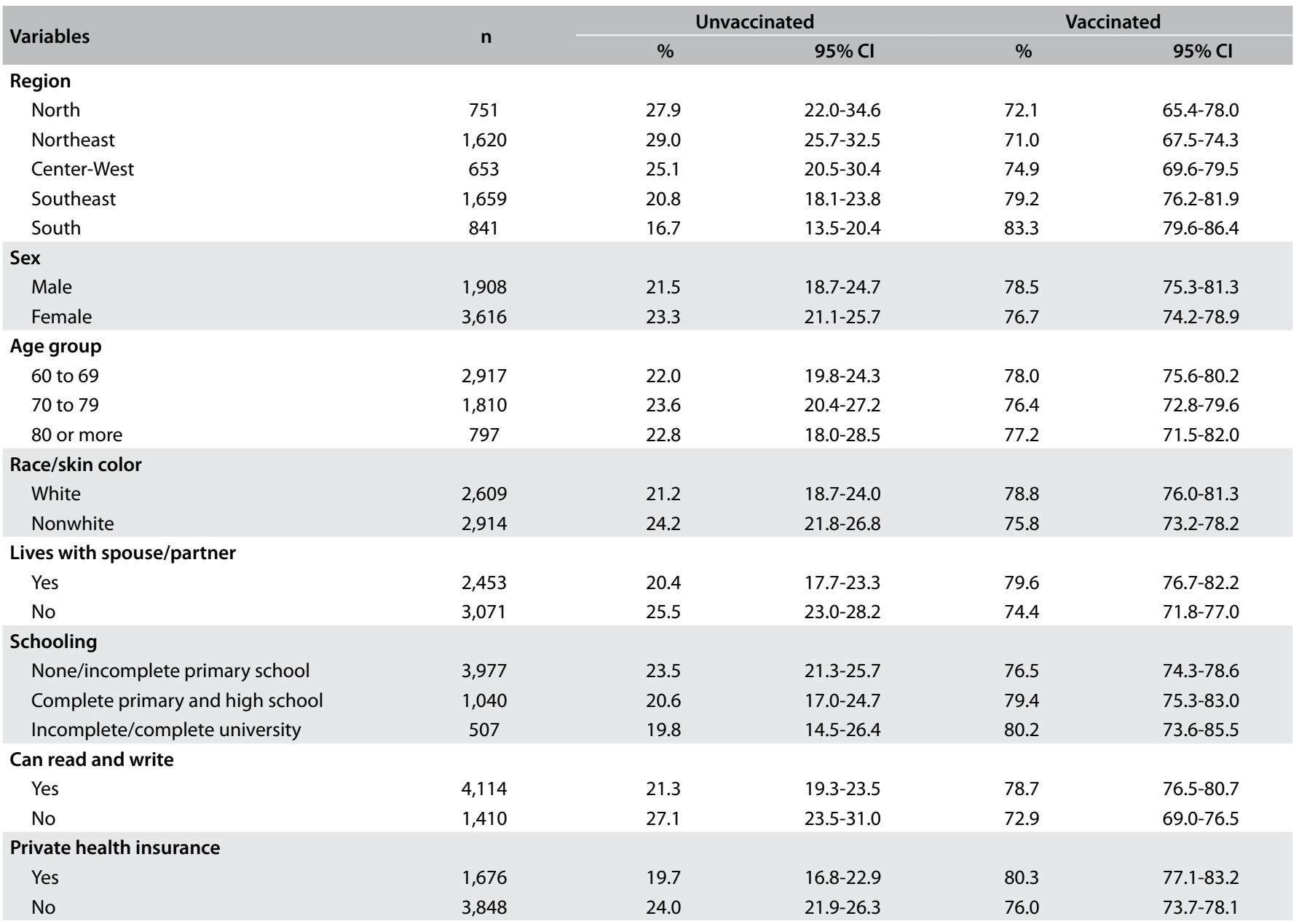

$\mathrm{Cl}=$ confidence interval $(\mathrm{a}=0.05)$, considering the study design effect. 
The main reasons for non-vaccination were fear of a reaction $(28.6 \%$; 95\% CI:24.9-32.6), rarely having the flu (22.0\%; 95\% CI: 18.9-25.4) and not believing in the protection of the vaccine (12.3\%; 95\% CI: 9.5-15.8) (Figure 1).

The prevalence of non-vaccination among elderly people with hypertension was lower than the rates found for elderly people in general and for those who reported not having hypertension (27.4\% and $31.9 \%$, respectively).

\section{DISCUSSION}

In the present study, the prevalence of vaccination against influenza among elderly people with hypertension was lower than what was expected for the general population of elderly people, given that the goal in 2013 was to vaccinate at least $80 \%$ of all individuals $\geq 60$ years of age. ${ }^{11}$ Considering the greater contact of this group with healthcare services, ${ }^{12,15}$ the absolute number of unvaccinated individuals was high. Previous studies also found that there were no associations between the vaccination rate and sex, ${ }^{12,16,18,19}$ age group ${ }^{18}$ or schooling. ${ }^{18,19}$ Sato et al. ${ }^{19}$ found that the chance of having been vaccinated was greater among elderly people registered with the Family Health Program.

Regarding regional differences, the southern and southeastern regions of Brazil present socioeconomic differences in relation to the northeastern region. This may be reflected in access to healthcare services and, consequently, to information and counseling regarding the importance of vaccination. Moreover, the seasonality of influenza is more pronounced in the more southerly regions. In contrast, in northeastern Brazil, the peaks of the disease occur prior to the period when vaccination campaigns have been run, ${ }^{20}$ and this may have had an impact on the effectiveness of such campaigns as well as on the perceptions of elderly people regarding the protection offered by the vaccine, which thus will have had a negative influence on adherence.

The reasons for non-vaccination given by these elderly people with hypertension were similar to those found for the older population in

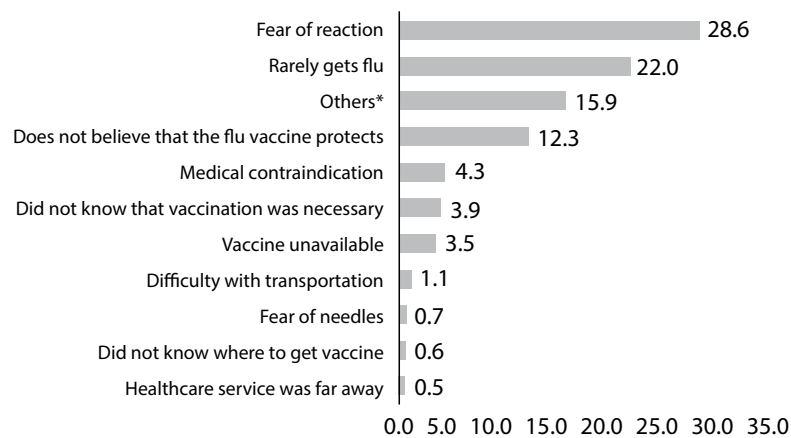

*Others: Did not have anyone to accompany him/her to healthcare service, had financial difficulties and other reasons not detailed in National Health Survey.

Figure 1. Distribution of reasons for non-adherence to vaccination against influenza among elderly people with hypertension. National Health Survey, 2013. general. ${ }^{18,19}$ Fear of side effects falsely attributed to the vaccine, not considering it important and having insufficient information regarding the benefits were the main reasons given. ${ }^{12,21}$ Counseling by healthcare professionals has been positively associated with vaccination and should be used as a strategy for improving knowledge among elderly people regarding both the disease and the vaccine.

\section{CONCLUSION}

The main reasons for non-vaccination (fear of a reaction, belief that influenza is a rare event, belief that the vaccine does not offer protection and fear of needles) accounted for more than $60 \%$ of the reasons given by these elderly people. These findings underscore the need for health professionals to explain to the population what the benefits of the vaccine are, regarding prevention of severe influenza (its protective effect and possible reactions) and secondary prevention of cardiovascular events. Increasing the prevalence of vaccination among elderly people with hypertension and other cardiovascular diseases is of fundamental importance within the realm of public health, as a strategy for reducing occurrences of complications and deaths associated with infection by the influenza virus.

\section{REFERENCES}

1. World Health Organization (WHO). Hypertension. Fact sheets. Available from: https://www.who.int/news-room/fact-sheets/detail/hypertension. Accessed in 2020 (Mar 2)

2. Firmo JOA, Mambrini JVM, Peixoto SV, et al. Adequate control of hypertension among older adults: ELSI-Brazil. Rev Saude Publica. 2018;52(Suppl 2):13s. PMID: 30379290; doi: 10.11606/s1518-8787.2018052000646.

3. Malta DC, Gonçalves RPF, Machado ÍE, et al. Prevalência da hipertensão arterial segundo diferentes critérios diagnósticos, Pesquisa Nacional de Saúde [Prevalence of arterial hypertension according to different diagnostic criteria, National Health Survey]. Rev Bras Epidemiol. 2018;21(Suppl 1):e180021. PMID: 30517472; doi: 10.1590/1980-549720180021.supl.1.

4. Andrade SSA, Stopa SR, Brito AS, et al. Prevalência de hipertensão arterial autorreferida na população brasileira: análise da Pesquisa Nacional de Saúde, 2013. Epidemiol Serv Saúde. 2015;24(2):297-304. doi: 10.5123/ S1679-49742015000200012.

5. Centers for Disease Control and Prevention (CDC). People at High Risk For Flu Complications. Available from: https://www.cdc.gov/flu/ highrisk/index.htm. Accessed in 2020 (Mar 2).

6. Clar C, Oseni Z, Flowers N, Keshtkar-Jahromi M, Rees K. Influenza vaccines for preventing cardiovascular disease. Cochrane Database Syst Rev. 2015;(5):CD005050.PMID:25940444; doi: 10.1002/14651858.CD005050.pub3.

7. Smith SC Jr, Benjamin EJ, Bonow RO, et al. AHA/ACCF Secondary Prevention and Risk Reduction Therapy for Patients With Coronary and Other Atherosclerotic Vascular Disease: 2011 Update: A guideline from the American Heart Association and American College of Cardiology Foundation. Circulation. 2011;124(22):2458-73. PMID: 22052934; doi: 10.1161/CIR.0b013e318235eb4d. 
8. National Clinical Guideline Centre (UK). Chronic Heart Failure: National Clinical Guideline for Diagnosis and Management in Primary and Secondary Care: Partial Update [Internet]. London: Royal College of Physicians; 2010. (NICE Clinical Guidelines No. 108). PMID: 22741186.

9. Bocchi EA, Marcondes-Braga FG, Ayub-Ferreira SM, et al. Sociedade Brasileira de Cardiologia. III Diretriz brasileira de insuficiência cardíaca crônica. Arq Bras Cardiol. 2009;92(6 supl.1):1-71. Available from: http://www.scielo.br/ pdf/abc/v93n1s1/abc93_1s1.pdf. Accessed in 2020 (Feb 3).

10. Modin D, Claggett B, Joergensen ME, et al. The flu vaccine and mortality in hypertension. A Danish nationwide cohort study. European Heart Journal. 2019:40(Suppl.1):ehz748.0047. doi: 10.1093/eurheartj/ehz748.0047.

11. Coordenação Geral do Programa Nacional de Imunizações, Departamento de Vigilância Epidemiológica, Secretaria de Vigilância em Saúde, Ministério da Saúde. 21a Campanha Nacional de Vacinação Contra a Influenza: informe técnico. Brasília: Ministério da Saúde; 2019. Available from: https://portalarquivos2.saude.gov.br/images/pdf/2019/fevereiro/28/ Informe-Cp-Influenza-28-02-2019-final.pdf. Accessed in 2020 (Feb 3).

12. Francisco PMSB, Donalisio MR, Barros MBA, Cesar CLG, Carandina L, Goldbaum M. Fatores associados à vacinação contra influenza em idosos [Factors associated with vaccination against influenza in the elderly]. Rev Panam Salud Pública. 2006;19(4):259-64. Available from: https://www. scielosp.org/article/rpsp/2006.v19n4/259-264/. Accessed in 2020 (Feb 3).

13. Campos EC, Sudan LC, Mattos ED, Fidelis R. Fatores relacionados à vacinação contra a gripe em idosos: estudo transversal, Cambé, Paraná, Brasil [Factors associated with influenza vaccination among the elderly: a cross-sectional study in Cambé, Paraná State, Brazil]. Cad Saude Publica. 2012;28(5):878-88. PMID: 22641511; doi: 10.1590/S0102-311X2012000500007.

14. Malta DC, Stopa SR, Pereira CA, et al. Cobertura de Planos de Saúde na população brasileira, segundo a Pesquisa Nacional de Saúde, 2013 [Private Health Care Coverage in the Brazilian population, according to the 2013 Brazilian National Health Survey]. Cienc Saude Colet. 2017;22(1):179-90. PMID: 28076541; doi: 10.1590/1413-81232017221.16782015.

15. Matta SR, Bertoldi AD, Emmerick ICM, et al. Fontes de obtenção de medicamentos por pacientes diagnosticados com doenças crônicas, usuários do Sistema Único de Saúde [Sources of medicines for chronic patients using the Brazilian Unified National Health System]. Cad Saude Publica. 2018;34(3):e00073817. doi: 10.1590/0102-311×00073817.

16. Bacurau AGM, Francisco PMSB. Prevalência de vacinação contra a influenza em idosos brasileiros com doenças crônicas [Prevalence of influenza vaccination in elderly Brazilian with chronic diseases]. Cad Saude Publica. 2019;35(4):e00230518. PMID:31066781; doi: 10.1590/0102-311×00230518.

17. Souza-Júnior PRB, Freitas MPS, Antonaci GA, Szwarcwald CL. Desenho da amostra da Pesquisa Nacional de Saúde 2013. Epidemiol Serv Saúde. 2015;24(2):207-16. doi: 10.5123/S1679-49742015000200003.

18. Bof de Andrade F, Sayuri Sato AP, Moura RF, Ferreira Antunes JL. Correlates of influenza vaccine uptake among community-dwelling older adults in Brazil. Human Vaccin Immunother. 2017;13(1):103-10. PMID: 27690757; doi: 10.1080/21645515.2016.1228501.
19. Sato APS, Antunes JLF, Lima-Costa MFF, Bof de Andrade F. Influenza vaccine uptake among older adults in Brazil: Socioeconomic equality and the role of preventive policies and public services. J Infect Public Health. 2020;13(2):211-5. PMID: 31431425; doi: 10.1016/j.jiph.2019.07.022.

20. Alonso WJ, Viboud C, Simonsen $L$, et al. Seasonality of influenza in Brazil: a traveling wave from the Amazon to the subtropics. Am J Epidemiol. 2007;165(12):1434-42. PMID: 17369609; doi: 10.1093/aje/kwm012.

21. Centro de Vigilância Epidemiológica (CVE) "Prof. Alexandre Vranjac". Informe Técnico da Campanha Nacional de Vacinação para o Idoso 2001. São Paulo: CVE; 2001.

Authors' contributions: Bacurau AGM: conceptualization (equal), formal analysis (equal), methodology (equal), visualization (equal), writing-original draft (equal) and writing-review and editing (equal); and Francisco PMSB: conceptualization (equal), formal analysis (equal), methodology (equal), visualization (equal), writing-original draft (equal) and writing-review and editing (equal). All authors approved the final version of the manuscript for publication

Acknowledgements: We thank the Ministry of Health and the Brazilian Institute for Geography and Statistics (Instituto Brasileiro de Geografia e Estatística, IBGE) for making data available from the National Health Survey 2013 (Pesquisa Nacional de Saúde 2013, PNS 2013). We also thank the Coordination Office for the Improvement of Higher Education Personnel (Coordenação de Aperfeiçoamento de Pessoal de Nível Superior, CAPES) for the grant awarded to A.G.M. Bacurau

Short communication derived from the research project "Studies on vaccination against influenza in the elderly and individuals with chronic diseases", referring to the doctoral thesis to be defended by Aldiane Gomes de Macedo Bacurau in February 2021, within the Postgraduate Program on Collective Health of the School of Medical Sciences, Universidade Estadual de Campinas

\section{Sources of funding: None \\ Conflict of interest: None}

Date of first submission: March 6, 2020

Last received: May 10, 2020

Accepted: May 15, 2020

\section{Address for correspondence:}

Aldiane Gomes de Macedo Bacurau

Departamento de Saúde Coletiva, Universidade Estadual de Campinas (UNICAMP)

R. Tessália Vieira de Camargo, 126

Cidade Universitária Zeferino Vaz — Campinas (SP) — Brasil

CEP 13083-887

Tel. (+55 19) 3521-9244

E-mail: aldianemacedo@gmail.com 